\title{
Construction of an Affordable, Tactile, Didactical and Inclusive Material Aimed to Teach Biology and Biotechnology to Blind and Visually Impaired Students
}

\author{
Lourena P. Marinho, Helena C. Castro, Eloah C. D. Lyrio, Cristina M. Delou \\ LABiEMol-PPBI, Biology Institute, Federal Fluminense University, Niterói, Brazil \\ Email: hcastrorangel@yahoo.com.br, cristinadelou@globo.com
}

How to cite this paper: Marinho, L. P., Castro, H. C., Lyrio, E. C. D., \& Delou, C. M. (2016). Construction of an Affordable, Tactile, Didactical and Inclusive Material Aimed to Teach Biology and Biotechnology to Blind and Visually Impaired Students. Creative Education, 7, 2666-2677. http://dx.doi.org/10.4236/ce.2016.717250

Received: August 31, 2016

Accepted: November 13, 2016

Published: November 16, 2016

Copyright $\odot 2016$ by authors and Scientific Research Publishing Inc. This work is licensed under the Creative Commons Attribution International License (CC BY 4.0). http://creativecommons.org/licenses/by/4.0/

\begin{abstract}
The inclusion process should guarantee teaching and learning of all students including those with special needs. Currently, didactical materials with focus in attending blind and visually impaired students are still in need, especially those for teaching Biology complex themes (e.g. Arthropods). The purpose of this work is to describe the production and the in loco test of a kit containing an accessible, tactile, didactical and inclusive material about Arthropods targeting this public, which allows to explore the biotechnological potential of these animals. The kit was constructed with affordable materials approached in two- and three-dimensional perspectives. We tested it with seven students with visual deficiency from a Brazilian public school. To verify the efficiency of the material, we applied evaluative questionnaires regarding the theme pre- and post-periods from using the material. The results revealed that the use of this didactical material helps the blind and visually impaired student to understand the complexity of Arthropods anatomy and its morphological characterization to apply for biotechnology purposes.
\end{abstract}

\section{Keywords}

Blindness, Educational Material, Biotechnology

\section{Introduction}

Inclusion in schools must occur to attend all students respecting their uniqueness, including social, intellectual and/or physical features, among others. Inclusive education addresses several issues especially those involving teaching people with special needs. It is based on the fact that people with disabilities are able to learn, and, therefore, they 
should not be limited to education in specialized environments. Instead they should interact with everyone and have access to everything regarding and requested by their educational process (Brazil, 1988; Mantoan, 2005). Among them are those with visual impairment (Brazil, 1988; Sánchez, 2005). Currently, the visual impairment is described and classified into two groups:

a) low vision, with less than $6 / 18$ of light perception ability, and use of optical or non-optical equipment (OMS, 1989; Smith, 2008).

b) blindness, with serious or complete affected vision abilities including identifying color, size, distance, shape, position or movement (Delou et al., 2012).

Another criterion for classification of blindness is the age that the person was affected: congenital blindness (<two years) and acquired blindness (>two years) (Smith, 2008). This criterion is important because children who lose their sight after two years old maintain their visual memory. This influences the formation of concepts and other learning aspects that are constructed based on this previous memory and concepts. Children with congenital blinding request the deepest information and strategies that present and explain the very basic concepts. These children will present more developed tactile, auditory, kinesthetic and olfactory abilities due to the constant use for decoding information. This development is not a compensatory phenomenon but a result of a constant use that should be explored on the teaching and learning process (Freitas, 2007; Delou et al., 2012; Smith, 2008).

According to the literature, the current contents of several disciplines including Biology are usually presented in a visual format, with different representations including drawings, charts, slides among others that hugely depend on sight. Students with visual limitations do not have proper access of these contents, and, therefore, the knowledge that they provide. This creates a "scholar" isolation that generally leads to their dropping out of school.

To prevent this situation and guarantee that the visually impaired students have their right to education fully granted, teaching materials and resources must be constructed exploring other senses (e.g. tactile). It is important to notice that the access to knowledge, communication and learning depends on the quality, variety and suitability of these materials. On that matter, concrete materials reduce the abstraction in learning processes, also reducing oral statements. They fulfill the needs of the visually impaired student, also including the others with no special needs (Delou et al., 2012; Brazil, 2009).

Teaching resources for visually impaired students must hold important features including following proper dimensions and details such as not be too large, so the student can understand them all (Delou et al., 2012; Cerqueira \& Ferreira, 1996). The components of the didactic material should be resistant to constant touching, and simple to handle as much as riding. It should display Braille and/or oral explanation to allow independent use of the material (Delou et al., 2012).

To promote communication and understanding among all students, it is essential to have visual and tactile stimulus that meets different visual conditions. Therefore, contrasting colors, textures and sizes are more suitable to guarantee their usefulness and 
meaningfulness (Delou et al., 2012).

Interestingly, these tactile materials can be very useful when approaching complex Biological themes such as biotechnology. This area approaches the use of living beings for the production of materials and products for human and animal use. This context includes the arthropods (e.g. spiders, scorpions, insects) that are found in different environments and present a complex anatomy and physiology. They are segmented, present exoskeleton and jointed appendages, and due to its adaptive success, they survive in virtually all environments, such as terrestrial, marine, freshwater and air habitats (Ruppert \& Barnes, 2005).

These animals have an economic, medical and ecological importance, since they may be used for different purposes (e.g. food production). Some of them are great pollinators, while others are considered agricultural pests, as they destroy crops causing a large expenditure of money with pesticides. They may also act as vectors of important diseases to humans and domestic animals (e.g. Disease Chagas disease, fever, bubonic plague, typhoid fever, among other) (Ruppert \& Barnes, 2005; Edgecombe, 2010).

Due to its variety and complexity, the understanding of Arthropods and its features is difficult for visually impaired students. Thus, inclusive materials that allow the analysis of morphological and structural characteristics of these animals, in simple, playful and inclusive way, are urgent in the school inclusive environment.

In this work, we aim at the construction of a kit about arthropods with 2- and 3-dimensional tactile and didactical materials that attend the needs of visual impaired students. On that purpose, we tested it with blind students to verify the feasibility of the material to help on teaching this public.

\section{Methods}

For preparing the didactical perspective of the kit, simple and accessible materials were used, including: fabrics (leather, satin, denim, etamine velvet, hemp and synthetic), felt, buttons, Velcro (rough tape), searing lines (different colors), Twine, Cardboard, Glue Jeans and Scissors.

Each anatomical part of animals of different species was assembled with different fabrics. However, in the case of structures such as antennae, eyes and legs, which are common to many of them, we used strings or lines, buttons and lines respectively following a standardized texture in all animal models to facilitate student understanding. The anatomical parts were made with different textures and colors, so that students with visual disabilities can differentiate and identify the parts that make up each animal through touch. Strong and vivid colors were used to attend students with low vision but not totally blind.

The material was constructed to enable the student to obtain information in a clear and dynamic way and to understand how the insects are. Thus, the material constructed in a puzzle format with all morphological parts of the animals attachable to a piece of velcro (A4 sheet) which serves as support. The material allows construct and disconstruct the animal, so the students may observe each part individually, and to ex- 
plore them completely.

Six models were also built in 3D with homemade plastic resin to allow the identification of the distribution of all parts in the animal. The application and evaluation of the material were undertaken in five stages and are described in Table 1. A classical book was used as reference for establishing the right answers for the questions (Ruppert \& Barnes, 2005).

\section{Subjects}

To verify the inclusion feature of the didactical material, we tested it with the target public-visually impaired and low vision students from public high schools in the state of Rio de Janeiro. The project was submitted and approved by the Ethics Committee of the Universidade Federal Fluminense-CEP/FF under the CAAE number: 0364.0.258.000-11. We asked those with eighteen years old or higher and those responsible for the other students under 18 to sign the Informed Consent Form. Seven visually impaired students participated in this study including five blind and low vision, a deaf-blind (with mild deafness and blindness) and a non-visually impaired. The test has begun with an explanation about the theme Arthropods. Then, the students were randomly divided into two groups: a) four students who used the 2D- and 3D materials and b) three students with no material offered.

Table 1. Evaluation of the didactical material.

\begin{tabular}{|c|c|}
\hline Step & Dynamic evaluation \\
\hline & $\begin{array}{l}\text { A questionnaire containing seven questions was orally presented and } \\
\text { the responses about students' preconceptions about arthropods were } \\
\text { recorded and transcribed. }\end{array}$ \\
\hline $\begin{array}{l}\text { Pre-Test questionnaire } \\
\text { and plasticine use }\end{array}$ & $\begin{array}{l}\text { Plasticine was offered to both visually impaired and non- visually } \\
\text { impaired students so that they could represent arthropods according } \\
\text { to their preconceptions. After that, they shared their models raising } \\
\text { discussions about the anatomy of arthropods and their importance to } \\
\text { the environment. }\end{array}$ \\
\hline $\begin{array}{l}\text { Test kit } \\
\text { (2D and } 3 \mathrm{D} \text {-didactic material) }\end{array}$ & $\begin{array}{l}\text { We presented the group Phylum Arthropoda to students. They were } \\
\text { divided into two group: a) a group that interacted with 2D-material, } \\
\text { along with a brief explanation of each taxon and the importance to } \\
\text { the environment they live in. This group also interacted with the } 3 \mathrm{D} \\
\text { models having the size and distribution of parts perspective in the } \\
\text { whole structure. b) the other group had no material offered, but the } \\
\text { explanation of each taxon. }\end{array}$ \\
\hline $\begin{array}{l}\text { Post-test conceptions by using } \\
\text { plasticine and questionnaire }\end{array}$ & $\begin{array}{l}\text { In order to assess whether there was any change in the primary } \\
\text { conceptions after the presentation of the material, students were } \\
\text { asked again to represent each arthropod using plasticine and to } \\
\text { answer the questionnaire. }\end{array}$ \\
\hline $\begin{array}{l}\text { Post-test evaluation of the } \\
\text { remaining conceptions and } \\
\text { students' opinions about } \\
\text { the material }\end{array}$ & $\begin{array}{l}\text { In order to analyze the remaining conceptions one month after the } \\
\text { latest discussion } 4^{\text {th }} \text { step about the topic, we apply the post-test } \\
\text { questionnaire once more as well as the questionnaire regarding } \\
\text { their opinion about the } 3 \mathrm{D} \text { models as complements to the material. }\end{array}$ \\
\hline
\end{tabular}




\section{Results and Discussion}

Here in we produced an inclusive kit with tactile teaching materials including six sheets representing six arthropods, including a grasshopper, butterfly, beetle, wasp, gnat, and bedbug. These animals have all the classic features of an arthropod, commonly described in classical textbooks (Figure 1).

The dynamic of constructing the two-dimensional models (slides) is similar to a puzzle to offer the student the opportunity to explore each individual anatomical part and provide mental structuring of the student regarding the morphology of the insect (Figure 2(A); Figure 2(B)). On the back of each sheet there is a legend in Braille describing the animal and its ecological, economic and pathological importance (Figure $2(C))$. The subtitle also allows the students to access information independently.

Tridimensional models were created as described on methodology section and, similar to the figures represented in the two-dimensional model to provide a spatial structure on the distribution of the anatomical parts and the details that both the two-dimensional material and insects in actual size cannot provide (Figure 2(D)). Before the application of the material, a pre-test in the form of structured interview questionnaire was also applied. This methodology was chosen because the oral form offered to the students freedom to formulating responses without concerning about written/structured terms compared to the Braille/written form.

After the pre-test questionnaire, visually impaired, low vision and non-visually impaired students were invited to represent the insects according to their individual conception, using plasticine (Figure 3(E)). Literature (Medin \& Smith, 1984) considers some concepts as descriptions of parts to understand the whole animal body structure.

After they made models of arthropods using plasticine (Figure 3), we asked them to look/touch all models to promote among them the comparison and discussion on how the anatomy of an arthropod is. According to some authors (Ormelezi, 2000), the formation of a concept would not be possible without language, because it represents the
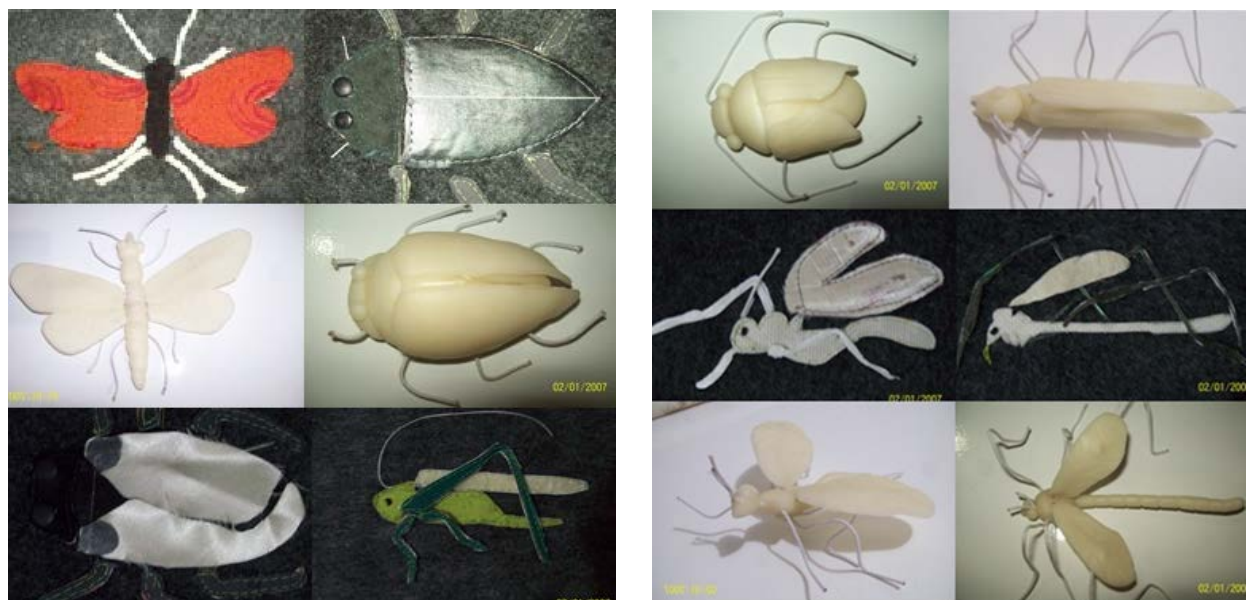

Figure 1. Inclusive Educational material showing the six 2D blades with the following animals: butterfly, beetle, bug, grasshopper, Wasp and Mosquito (left) and the corresponding three-dimensional models (right). 

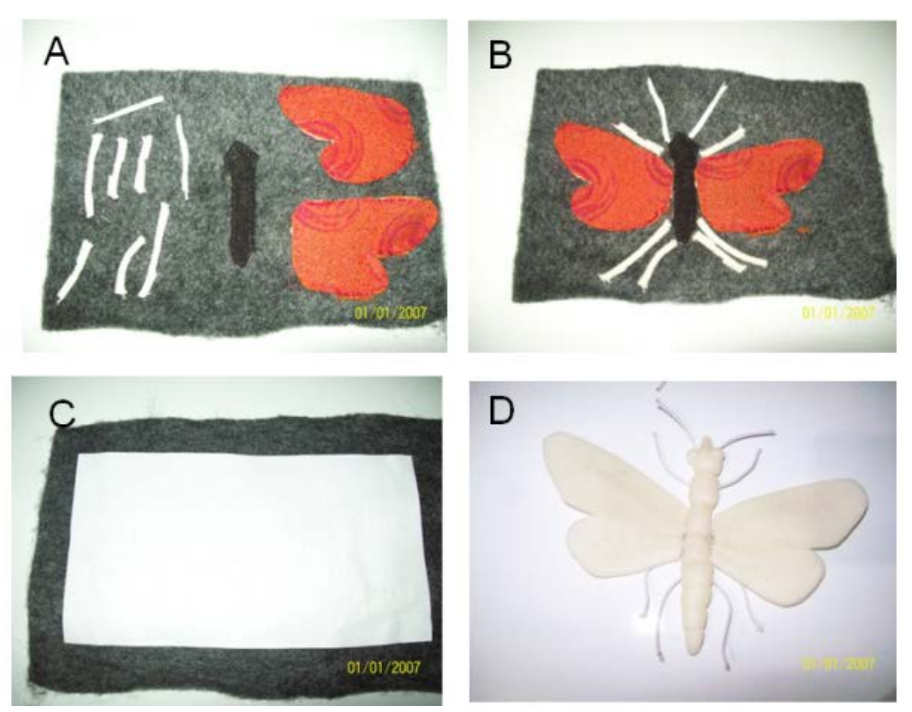

Figure 2. The inclusive tactile teaching materials in 2D and 3D. Material representing the anatomical parts of a separately or together (A) (B) with the bug. Subtitle on the back (C) and the three-dimensional model (D).
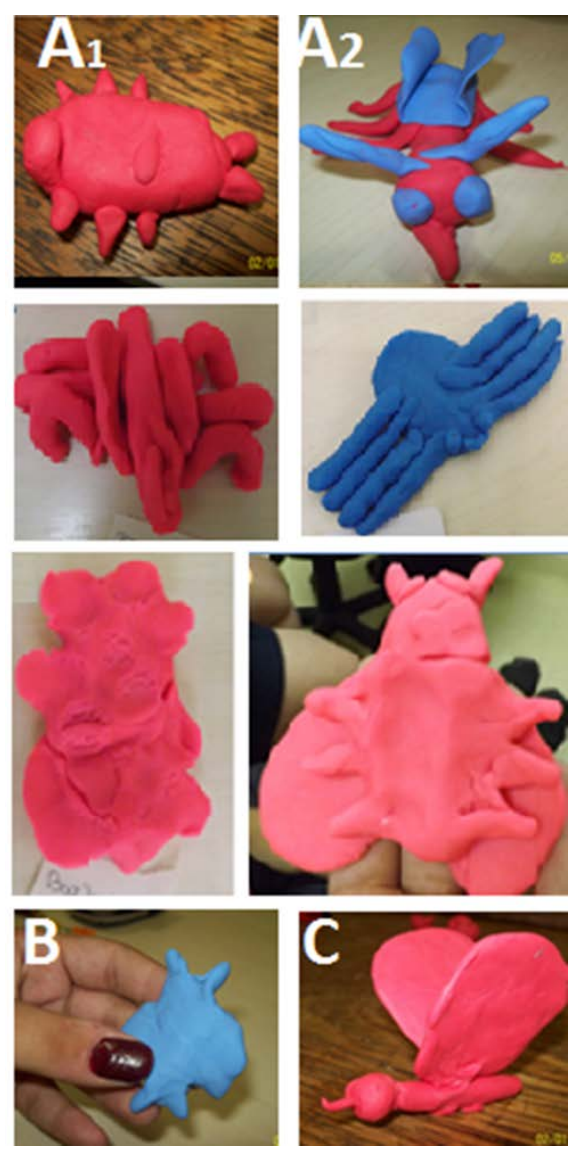

Figure 3. Comparison of models of Arthropods constructed by the students using plasticine. A1-2) Models of produced by some visually impaired students before (A1) and after (A2) using the kit of bee, arachnidan and mosquito. (B) and (C) Models of butterfly produced without (B) or using $(\mathrm{C})$ the kit. 
reality and influences of the main factors that will guide the construction of the concept.

After this conversation, students were divided into two groups, and we presented the two-dimensional material to only one group as describe by Table 1 .

Initially the visually impaired students had some difficult in touching the materials depending on the spatial position of the figure, as some had the arthropod lateral view. After surpassing this difficulty, the animal structure was deconstructed and each anatomical part was presented individually, which seems to facilitate their understanding (Figure 4).

Thus, the in loco test allowed to observe that the two-dimensional models did not meet all spatial orientations necessary to understand the animal. This could hinder a complete understanding of the animal complexity. In order to offer a better access of the anatomical information, we gave the $3 \mathrm{D}$-models previously prepared that were compared to the 2D-material of the kit (Figure 4). In order to verify variations in the students' concepts, both student groups were invited once more to represent the arthropods using plasticine (Figure 3).

Interestingly, the analysis of the models from the group that did not use the kit revealed no precise location of the arthropods anatomical parts (Figure 3(B)). There were noticed the absence of the anatomic division (head, chest and abdomen) and incorrect number of legs. Despite resembling the real size of the animal, the models did not offer many structural details (Figure 3(B)). Apparently, the exclusive use of oral language with this group did not meet the whole comprehension of the arthropods and
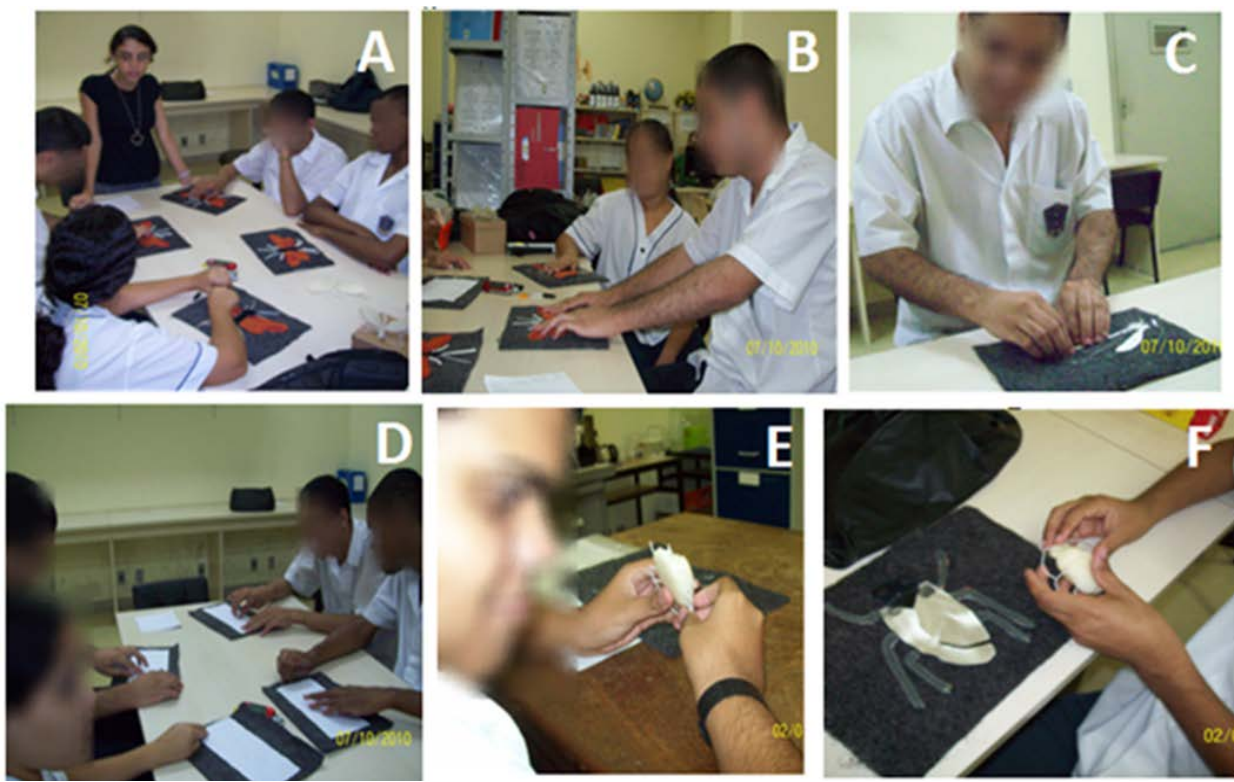

Figure 4. Application of the kit with the 2D (up) and 3D (down) tactile material. A-General Explanation of the class and its importance; B-Students testing the material; C-Student exploring parts testing that 2D-material; D-Students reading the summary in Braille after this material; E-Student blind exploring a 3D model; F-Students using the 3D model to understand the $2 \mathrm{D}$ tactile material. 
their anatomical complexity. This is in accord to the literature, which says that touching is important to offer the knowledge for visually impaired students as well as for allowing their concept construction (Batista, 2005).

Differently, the analysis of the models revealed significant differences detected in the plasticine models of the group that used the kit. This analysis showed an increase of the anatomic details in the representation such as the division into head, thorax and abdomen, which were not presented before, with a direct correspondence in relation to the location of anatomical structures of the two-dimensional and three-dimensional models (Figure 3(A)).

Interestingly, the number of appendages (e.g. legs, wings and antennas) was also correctly represented by these students. Thus, we may conclude that this tactile process help on the "structural vision" of all student (visually impaired or not). According to literature (Boni \& Quaresma, 2010), evaluating questionnaires through the speech allows the perception and analysis of the degree of confidence in the answers. Therefore we chose the use of questionnaires in the form of interview instead of using Braille, which could led to a wrong analysis due to a wrong written/structured responses.

Currently, few studies are described concerning student conceptions about arthropods theme. According to the literature, students have different misconceptions about arthropods. They are generally simply classified as "insects" or "non-bugs", and related to a negative concept (e.g. harmful and useless), which should be discussed (Alves et al., 2006; Modro et al., 2009). On that matter, the teacher should discuss about these misconceptions as these animals have an important role in a global and ecological perspective that should not be ignored.

Table 2 showed our pre-test evaluation about the general knowledge of the students on arthropods. According to our high school textbook used in this study arthropods are segmented animals, covered by an exoskeleton and with jointed appendages (Ruppert \& Barnes, 2005; Alves et al., 2006). The analysis of the answers to the question "What are arthropods?" revealed that most of visually impaired students consider arthropods just

Table 2. Comparison of answers about arthropods from visually and blind impaired students, and other students in the Pre-test questionnaires.

\begin{tabular}{|c|c|c|}
\hline \multirow{2}{*}{ Question } & \multicolumn{2}{|c|}{ Students } \\
\hline & Visually Impaired & Non-Visually Impaired \\
\hline $\begin{array}{l}\text { What are } \\
\text { Arthropods? }\end{array}$ & $\begin{array}{l}\text { "Arthropods! I guess I do not know exactly } \\
\text {... but I like the prefix I m translating the } \\
\text { Portuguese has something to do with feet } \\
\text { or... I do notknowwhat it is ... arthro" }\end{array}$ & $\begin{array}{l}\text { "A taxonomic philo of animals } \\
\text { with jointed legs." }\end{array}$ \\
\hline $\begin{array}{l}\text { Are Arthropods } \\
\text { important? }\end{array}$ & "No no, because they eat the plants ..." & $\begin{array}{l}\text { "Yes, as some act as pollinators } \\
\text { (like butterflies) and others are } \\
\text { destructive to agriculture (as a } \\
\text { grasshopper)." }\end{array}$ \\
\hline $\begin{array}{l}\text { How is divided the } \\
\text { body of insects? }\end{array}$ & $\begin{array}{l}\text { "Ahm... Gee, has little head, little body } \\
\text { and ... anteninnas..." }\end{array}$ & "In head, thorax and abdomen." \\
\hline
\end{tabular}


animals with paws. As these students have no access of Arthropods visual context and don't know the meaning of the arthro, they failed to answer the question by analyzing the word. This result shows the importance of offering a tactile material to fulfill this gap of information.

Some studies show that humans generally have negative perceptions about arthropods. They project a sense of disgust, harmfulness and dangerousness, which is mostly culturally determined (Modro et al., 2009). The question that addressed the importance of insects revealed the students views about arthropods positive and negative aspects. As expected, the most frequent answer was related to the negative side (e.g. agricultural damage). Some students also talked about foods produced by these animals such as honey to justify their importance.

About the division of the insect's body, the most frequent responses were correct with the insect body divided into three regions: head, thorax and abdomen. An interesting structure was cited, tracheas that are responsible for respiration in insects. Despite not being correct, these responses show that students know some structures that may be present in the insects' body, just the location that was not well defined in their concept.

For some authors, the concept formation is not possible without language, because it orally represents reality and influences the main factors that guide the construction of the concept (Ormelezi, 2000). Therefore, at the end of the activities, it was immediately re-applied the questionnaire to evaluate if there were changes in the students' prior knowledge and the possible influence of using the material (Table 3).

In the first question "what are arthropods?", students who used the material had similar responses where these are animals with jointed legs. One student cited the presence

Table 3. Comparison of answers about arthropods from visually and blind impaired students, and other students in the Post-test questionnaires after using the kit.

\begin{tabular}{|c|c|c|c|c|}
\hline Question & \multicolumn{4}{|c|}{ Students } \\
\hline $\begin{array}{l}\text { What are } \\
\text { Arthropods? }\end{array}$ & $\begin{array}{l}\text { "What are arthropods? ... Ah ... It's } \\
\text { a kind of animal. An Animal Kingdom } \\
\text {... I cannot define... are animals of } \\
\text { the Animal Kingdom that is it." }\end{array}$ & "Are animals with jointed legs walking." & $\begin{array}{l}\text { "Are animals belonging } \\
\text { to the taxonomic filo." }\end{array}$ & $\begin{array}{l}\text { "Animals with } \\
\text { jointed legs." }\end{array}$ \\
\hline $\begin{array}{l}\text { Arthropods are } \\
\text { important? }\end{array}$ & $\begin{array}{l}\text { "Negative because they can transmit } \\
\text { diseases to humans and also does not } \\
\text { let us sleep, and positive ... ah ... the } \\
\text { honey bee they can use as a food } \\
\text { source." }\end{array}$ & $\begin{array}{l}\text { "The same thing they can be positive } \\
\text { or negative, because they can devour } \\
\text { crops, and positive because some may } \\
\text { also eat other insects, is to kill insects } \\
\text { that harm our health." }\end{array}$ & $\begin{array}{l}\text { "Yes, to be studied and } \\
\text { produce medicines that } \\
\text { prevent diseases that } \\
\text { come this insect." }\end{array}$ & $\begin{array}{l}\text { "Yes, as } \\
\text { pollinators." }\end{array}$ \\
\hline
\end{tabular}


of these joints as evolutionary characteristics (Table 3).

Students who did not use the material, both visually impaired and non-visually impaired students affirmed correctly that these animals are part of Kingdom Animalia. But with no characterization involving the joints as the other group did. This could infer that the material may be contributing to the perception/establishment of this concept.

This concept addressed not only the biological feature, but also the spatial concept, because the animal's anatomy is essential to their taxonomic classification and its application in daily life.

All students consider arthropods important, in a positive or negative way. The students answered in the pretest questionnaire relating these animals to agricultural and food products destruction. Differently in the post-test questionnaire, the students presented new justifications, such as the importance of pollination, arthropods as pathological agents and their role in ecology.

Some students could make correlations with ecological relationships such as mutualism, parasitism, predation and herbivorism. It is important to notice that in the back of the material there was a legend in Braille containing general information about the animal.

As the student included the importance of these animals to the environment, this may indicate that the material was able to transmit the content in an easy and understandable way.

All students answered correctly the division of the insect's body. However, the students who used the tactile teaching materials, anatomically localized the structures present in insect's body instead of answering about the division. Interestingly, those who had contact with the material presented answers with greater accuracy than the others probably due to the visual/tactile memory.

According to the literature, the lack of some complex concepts from the visually impaired individuals is due to lack of practical experiences (Nunes, 2004). These experiences allow them to understand the reality as occurred with the non-visually impaired people. In this work, we showed that our models briefly represented the reality. Our data showed that simple materials can assist visually and non-visually impaired students helping them with these complex themes.

In this work, we also tested how long we could observe the retaining of the information. Thus, after a month of testing material, the questionnaire was again administered as an interview, to evaluate the remaining knowledge of this activity. The "post-monthtest questionnaire evaluation" showed that all students remembered about the arthropods content. The answers from the group that had no contact with the material were not wrong, but only the students who used it had complete answers, reporting the location of structures present in each part of the arthropods body.

Different responses were observed in their answers, especially from the students who manipulated the material. This probably occurred due to the discussion among all students, after the activity. This suggested that the construction of concepts is dynamic, 
and the teaching-learning relationship is not structured only in conversations or in lectures, but occurs all the time. It is renewed and reconstructed with experienced and/or shared experiences (Ormelezi, 2000; Batista, 2005). Activities outside the classroom promote easier understanding of content than in biology classes (Orlando et al., 2009). In fact, only the change in tone of the teacher speech would create an environment more enjoyable for the student to learn. Therefore, using the strategy described herein with the plasticine may also help on "concreting" the knowledge.

After all the activities, a questionnaire was applied to know about the students opinions about the materials. Interestingly most of the responses were positive. We questioned whether the use of the material was feasible and useful. Importantly, all answered that its use is essential in high school, grading the material with grades between nine and ten.

We observed that the dynamic use of the material through the activities with concrete models led to a greater interest, and, apparently, to a greater assimilation of content. Students who haven't interacted with the kit also had a good result pointing the plasticine activity as a strategy to be used for teaching as well. However, spatial and structural learning was not as effective pointing our material as an important tool for teaching this complex theme.

It is important to notice that there was difficulty of some students to interpret the images on the two-dimensional material. This infers the need of a teacher/advisor for using this material, so he/she can assist them to locate and interpret the arthropods structures. The three-dimensional models were more self-explanatory than the $2 \mathrm{D}$ material, probably due to their clear and defined 3D structure limits.

This work allowed us to show that the application of models may help to teach the visually impaired student and clearly favored the teaching of complex themes.

\section{Acknowledgements}

We thank CAPES, CNPq, UFF and FAPERJ for the fellowships and financial support. We also thank Colégio Pedro II, Abreu, A.C.J. and Silva, G.C.C. for technical assistance.

\section{References}

Alves, L. F. A., Busarello, G. D, \& Giannott, I. S. M. (2006). Arthropods in Educational Materials Used in Schools Private High Schools in Cascavel/PR. Varies Scientia Magazine, 6, 107-120.

Batista, C. G. (2005). Concept Formation in Blind Children: Theoretical and Educational Implications, Issues Psychology: Theory and Research, 21, 7-15.

Boni, V., \& Quaresma, S. J. (2010). Learning to Interview: How to Do Interviews in Social Sciences. Electronic Journal of Post-Graduate in Political Sociology at UFSC, 2, 68-80.

Brazil (1988). Constitution of the Federative Republic of Brazil. Brasilia: Government Printing.

Brazil (2009). Resolution. Paragraph 4 of October 2, 2009. Ministry of Education.

Cerqueira, B. J., \& Ferreira, B. M. E. (1996). Teaching Resources in Special Education. Magazine Benjamin Constant, Published Scientific Technician Center for Research, Documentation and Information Institute Benjamin Constant (IBCENTRO/MEC).

http://www.ibc.gov.br/?catid=4\&itemid=47 
Delou, C. M. C., Machado, S., Mazza-Guimaraes, I., \& Castro, H. C. (2012). School of Inclusion: The Contribution of a Federal University to the Inclusive Education. Advances in Education, 1, 4-10.

Edgecombe, G. D. (2010). Arthropod Phylogeny: An Overview from the Perspectives of Morphology, Molecular Data and the Fossil Record. Arthropod Structure \& Development, 39, 7487.

Freitas, S. A. C. T. (2007). The Perception of Body Image in the Visually Impaired: A Comparative Study in Individuals Practicing Futsal for the Blind, Goalball and Not Doers, Aged Between 20 and 58 years. Monograph: Porto University.

Mantoan, M. T. E. (2005). The Time of the Turn. Inclusion. Journal of Especial Education, 24, 24-29.

Medin, D. L., \& Smith, E. E. (1984). Concepts and Concept Formation. Annual Review of Psychology, 35, 113-138. http://dx.doi.org/10.1146/annurev.ps.35.020184.000553

Modro, A. F. H., Costa, M. S., Maia, E., \& Aburaya, F. H. (2009). Entomological Perception by Teachers and Students in the Municipality of Santa Cruz do Xingu, Mato Grosso, Brazil. Biotemas Magazine, 2, 153-159.

Nunes, S. S. (2004). Concept Development in Congenitally Blind: Paths of Knowledge Acquisition. Master's Thesis, São Paulo: Institute of Psychology, São Paulo University.

OMS. World Health Organization. (1989). International Classification of Impairments, Disabilities and Handicaps, Ministry of Employment and Social Security. Lisbon: National Secretariat of Rehabilitation.

Orlando, T. C., Lima. A. R., Da Silva, A. M., Fuzissaki, A. N., Ramos, C. R., Machado, D., Fernandes, F. F. et al. (2009). A Planning Construction and Application of Didactic Models of Cell and Molecular Biology by Undergraduate Students in the Biological Sciences. Brazilian Journal of Education of Biochemistry and Molecular Biology, 1-7.

Ormelezi, E. M. (2000). The Ways of Acquiring Knowledge and Blindness: The Universe of the Body to the Symbolic Universe. MSc Thesis, São Paulo: Faculty of Education (USP).

Ruppert, F. R. S., \& Barnes, R. D. (2005). Zoology of Invertebrates-Introduction to Arthropoda (7th ed). São Paulo: Roca.

Sánchez, P. A. (2005). Inclusive Education: A Means to Build Schools for All in the Twenty-First Century. Journal of Special Education Inclusion, 1, 7-18.

Smith, D. D. (2008). Introduction to Special Education. Teach in Times of Inclusion (5th ed.). Oxford: Oxford University Press. 
Submit or recommend next manuscript to SCIRP and we will provide best service for you:

Accepting pre-submission inquiries through Email, Facebook, LinkedIn, Twitter, etc. A wide selection of journals (inclusive of 9 subjects, more than 200 journals)

Providing 24-hour high-quality service

User-friendly online submission system

Fair and swift peer-review system

Efficient typesetting and proofreading procedure

Display of the result of downloads and visits, as well as the number of cited articles

Maximum dissemination of your research work

Submit your manuscript at: http://papersubmission.scirp.org/

Or contact ce@scirp.org 